\title{
The role played by health resistance, coping response, and smoke damage perceptions in smoking threat appeal campaigns
}

\author{
Concetta Pirrone, ${ }^{1}$ Silvia Maria Platania, ${ }^{1}$ Sabrina Castellano, ${ }^{1}$ Shari Hrabovsky, ${ }^{2}$ \\ Pasquale Caponnetto, ${ }^{3,4}$ Elena Commodari ${ }^{1}$ \\ ${ }^{1}$ Department of Education Science, Catania, Italy; ${ }^{2}$ Pennsylvania State University, PA, USA; \\ ${ }^{3}$ Center of Excellence for the acceleration of Harm Reduction - CoEHAR, University of Catania, \\ Italy; ${ }^{4}$ University of Stirling, UK
}

\begin{abstract}
Threat appeal campaigns have been widely used to induce people to change their bad smoking habits by adopting a better approach in favor of a healthier lifestyle. Social marketers who create this kind of messages tend to believe in the persuasive power of fear arousal. For most people, fear has an important consequence on behavior, leading them to search for means of deleting or coping with the unhealthy behavior. As demonstrated by the Ordered Protection Motivation Model, individual differences such as health
\end{abstract}

Correspondence: Pasquale Caponnetto, University of Catania, Italy. E-mail: p.caponnetto@unict.it

Key words: Threat Appeal Campaigns; Smoking Damage; Health Resistance.

Acknowledgments: The authors wish to thank the Scientific Bureau of the University of Catania for language support.

Contributions: conceptualization: $\mathrm{CP}$ and PC; methodology: CP, SP, PC, CS software, validation, and formal analysis: SP, investigation, resources, data curation, writing, original draft preparation: EC, SH; writing, review and editing: $\mathrm{SH}$, supervision; project administration: $\mathrm{CS}$ and PC.

Conflict of interest: The authors declare no conflict of interest

Funding: None.

Availability of data and materials: Study data are available within the text.

Ethics approval and consent to participate: All subjects gave their informed consent for inclusion before they participated in the study conducted in accordance with the Declaration of Helsinki. The study was conducted in accordance with the ethical standards established by the Italian National Psychological Association and approved by the IERB of the Department of Education Sciences on 29 July 2019.

Received for publication: 1 November 2019.

Accepted for publication: 7 April 2020.

This work is licensed under a Creative Commons AttributionNonCommercial 4.0 International License (CC BY-NC 4.0).

CC Copyright: the Author(s), 2020

Licensee PAGEPress, Italy

Health Psychology Research 2020; 8:8652

doi:10.4081/hpr.2020.8652 resistance play an important role in determining, or not, a change of behavior when faced with the threat. This study explores the relationship between health resistance and attitude towards smoking behavior and examines the mediating impact of coping response and smoke damage perception in a sample of 260 university students, smokers and non-smokers. Results highlight that health resistance has an important direct effect on smoking attitude, but, it seems to be mitigated by the smoke severity of the damage shown in graphic images. The comparison between smokers and nonsmokers allowed us to understand the role of reactance in these two groups, and the significance that anti-smoking campaigns assume. Our results offer important suggestions for future decisions about social threat appeals campaigns.

\section{Introduction}

The annual report on smoking presented by the Observatory Smoking, Alcohol and Drugs (OssFAD), has estimated there are 933.1 million smokers worldwide (Pacifici, 2017). According to data provided by the World Health Organization (WHO, 2017), «tobacco smoke is the second leading cause of death in the world» (WHO, 2018) and every year is responsible for about 6 million deaths. If nothing is done, this figure seems set to grow, it is estimated that in 2030 it will surpass 8 million (Ministry of Heath, 2017). To put a stop to these growing numbers, in 2009 the WHO recommended the use of simple cigarette packaging, by printing of the brand only with standard characters, colors and sizes, prohibiting any use of images that made smoking attractive. However, somewhat contrary to plain packaging, in 2013 the WHO requested that large health warnings to be prominently placed on cigarette packaging. They also requested bans on tobacco advertising, promotion, and sponsorship. These recommendations are strongly opposed by the tobacco industry because any warnings about or bans on tobacco use can be highly effective in reducing tobacco use and initiation, and the industry will lobby heavily against even the minimal restrictions (WHO, 2013; p.33).

These alarming figures are at the root of the efforts made in recent years by different governments to realize threat appeal campaigns whose goal is to induce people to abandon their smoking habit for a healthier lifestyle (Paek et al., 2014). Many social marketers have been using successful threat appeals in antismoking campaigns using fear as the main tool of persuasion (Guttman \& Ressler, 2001). Threat appeals seek to modify attitudes, beliefs and behaviors in a targeted audience relying on the feeling of fear being aroused; the message shows the negative impact that smokers are likely to meet if they do not adopt the recommended behaviors (Beaudoin, 2002). Graphic labels on cigarette packs portray the severity of smoking-related diseases and can increase the viewer's perception of personal risk. By directing the smoker's 
attention to the threats reported on the pack, these graphic warnings increase the perception of potential harm and reduce the social appeal of cigarette smoking among young people and young adults (Germain et al., 2010; Moodie \& Ford, 2011). Despite widespread use, the effectiveness of fear appeals on the social markets remains contentious (Manyiwa \& Brennan, 2012). While many studies have concluded that the fear arousal improves persuasion (Hammond et al., 2002, 2007; O'Hegarty et al., 2006), other scholars (Erceg-Hurn \& Steed, 2011; LaVoie et al., 2017; Peters et al., 2007) stated that threat appeal reinforces the undesirable behaviour, probably because they trigger reactance and corresponding maladaptive responses. Furthermore, campaigns using high levels of fear appeals tend to evoke extreme emotional response, such as becoming hostile or depressed (Manyiwa \& Brennan, 2012).

Another issue concerns the type of images on cigarette packs in order to verify the ability of the smokers to recall the details: physical or social, low or high intensity damage. Here the results are in contrast, findings demonstrate that smokers report greater recall when they are exposed to highly intense messages that depict physical harm (Kang \& Lin, 2015; Rayner et al., 2015), while other results show the efficiency of appeals to social harm recall (Tanner et al., 1991). Ordered Protection Motivation Model (OPM), emphasized how individual difference can impact the reply to threat and modify a person's response. Recent research based on OPM states that, more than the kind of message - social or physical - it is crucial to investigate the role played by individual differences in determining the final effect of threat appeal on the possibility to adopt a healthier lifestyle.

Individual differences can be identified by measuring coping responses to protection motivation, sensation seeking (Schoenbachler \& Whittler, 1996), esteem and egocentrism used to manage terror, and health resistance. According to the previous research results, the effectiveness of messages containing fear appeals seems to be moderated by a person's health resistance. When developing our research aim, we considered the impact that health resistance and perceptions have in mediating the relationship between individual behaviors and coping response (DickinsonDelaporte \& Holmes, 2011). Therefore, our aim in this research was to explore the role of health resistance on smoke severity damage perceptions elicited by threat appeal, attitude towards smoking and adaptive/maladaptive coping, taking into account smoker and nonsmoker differences in a population of university students.

\section{Rationale and hypotheses}

Dickinson-Delaporte and Holmes (2011) emphasize the role that health resistance plays in moderating the relationship between individual behavior exhibited in the threat appeal and coping. They stress that in situations where individuals use an adaptive coping response to threat appeals, health resistance impacts their attitudes towards anti-smoking behaviors. The public's resistance to health prevention campaigns has recently increased (La Voie et al., 2017) showing that this can affect consumers' attitude on smoking. Identifying the underlying mechanisms leading to individual differences is interesting because it can improve our knowledge about success/failure of threat appeal campaigns, and, deepen our understanding of the role that health resistance plays in human behavior. Moreover, considering the lack of research providing the differences between non-smokers' and smokers' responses to threat appeals, there is a need to enhance the existing threat appeal campaign and behavior models to evaluate probable differences between these two groups.

Hence, our research question (RQ): Is there a significant difference between the smoker and non-smoker groups on the impact and mediation relationship of Severity Damage and the Coping Responses between Health Resistance and Attitude Towards Smoking?

Our research hypotheses are based on the previous literature.

Exposure to images that show damage to the viewer and the severity associated with images can have a significant effect in attenuating or modifying the relationship between health resistance and attitude towards smoking. (Figure 1). Our hypotheses are the following:

H1: Health Resistance produces a stronger direct effect on Smoking Attitudes.

H2: Fear and the consequent impact on Severity Damage have a mediating effect (indirect effect) on the relationship between Health Resistance and Smoking Attitudes.

H3: Adaptive Coping responses have a direct influence on the perception of Severity Damage $\left(\mathrm{H} 3_{\mathrm{a}}\right)$ and mediate the relationship between Health Resistance and Attitude Towards Smoking $\left(\mathrm{H}_{\mathrm{b}}\right)$ and between Severity Damage and Smoking Attitudes $\left(\mathrm{H} 3_{\mathrm{c}}\right)$.

\section{Materials and Methods}

\section{Participants}

Data were collected through convenience sampling. A total of 260 students were surveyed, (134 males, 51.5\%; 126 females, $48.5 \%)$ aged from 18 to $26(M=22.70 ; S D=3.54), 55 \%$ were smokers, who, on average, smoked $8.81(S D=3.23)$ cigarettes a day and had smoked for 6.94 years $(S D=5.43)$. The participants were students enrolled in various degree courses of their academic career at the University of Catania (Political sciences 22\%, Law 27\%, Psychology 25\%, Medicine/Paramedical 26\%). Participation was voluntary without compensation, we met them in different rooms study of Catania University and the main criteria was the age range indicated above, and the comparable population of smokers and nonsmokers. The data of the self-report questionnaires were collected in 3 months in an anonymously format, and the participants could withdraw their participation at any moment.

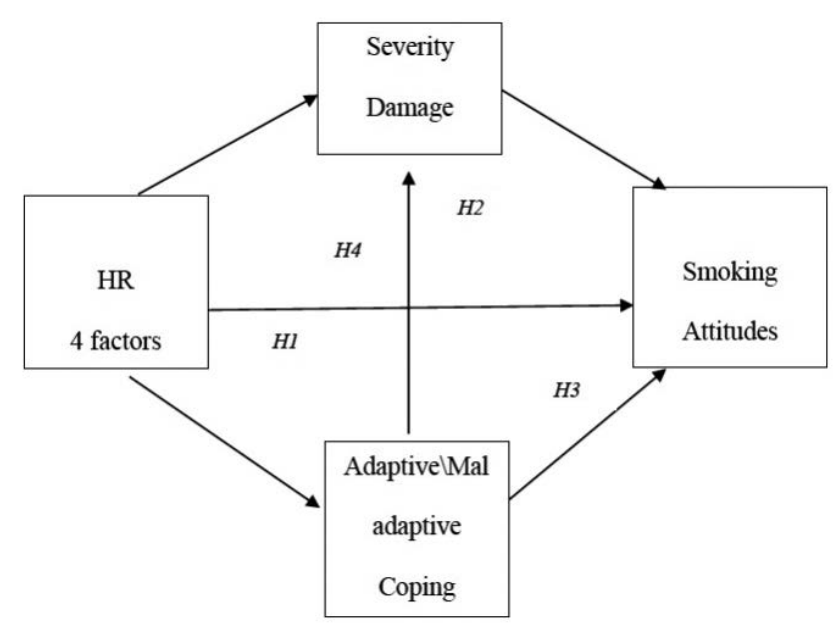

Figure 1. The hypothesized model. 


\section{Design and procedure}

In the present study we randomly showed to our sample two graphic images following, in part, the study carried out by Rayner, Baxter and Ilicic (2015), who selected 4 types of simulated-graphic images depicting physical (low/high intensity) and social (low/high intensity) threats aimed at identifying consumer recall of graphic fear based messages. Based on recent studies stating that high intensity physical threat appeals are more powerful than social threat appeals in preventing smoking (Germain et al., 2010), in defining our research we chose only two types of physical simulated-graphic images. As a means to emphasize the images shown in the threat appeals, the following headline was included at the top of the two images:

"Anti-smoking campaigns are based on the use of images similar to this. The objective is to raise awareness among the population about the damage caused by smoking. The aim is to induce smokers to stop smoking and to prevent other people from developing the addiction."

Immediately after, the participants were asked to rate the level of Severity Damage perceived damage pictured. After that, we submitted questionnaires on/about: health resistance, smoking attitude and Coping Response.

\section{Measure}

Smoke damage perception.

\section{Health resistance}

Health resistance relates to the theory of psychological reactance which suggests that people react against attempts to constrain their freedom of behaviors [Dickinson-Delaporte and Holmes, p.111]. Health Resistance was evaluated using a measure developed by Crossley (2002) and employed by DickinsonDelaporte and Holmes (2011). This scale examines four different factors/themes relating to resistance such as individual responsibility, skepticism, trust of authority and freedom/resistance, (Crossley, 2002). A five-point Likert scale (1 strongly disagree to 5 strongly agree) made of 17 items was used as in the original research. Sample items: "Even if I know something is bad for my health (e.g. smoking, sunbathing), if it gives me pleasure, it's worth $i t$ ", "I don't want to live without risk, that would not be living", "I'm sick and tired of being told what is good or bad for my health", "I have the right to risk my own health by engaging in whatever behaviour I choose". A single score of Health Resistance is obtained by summing the score of the 17 items, higher scores mean a greater resistance to health promotion, low scores indicate a low resistance.

\section{Coping responses}

In order to examine how chosen coping response (adaptive/maladaptive) impacts an individual's attitude towards the behavior of smoking, we used the scale developed by DickinsonDelaporte and Holmes (2011) which is based on the Sexually Transmitted Disease Maladaptive Behavior Scale by Tanner, Hunt, and Eppright (1991), and other coping measures used in studies examining adaptive/maladaptive coping modes (McCrae, 1984; Rppetoe \& Rogers, 1987). The scale includes 10 items (some of them were designed for reverse scoring), which measure the adaptive and maladaptive coping responses of young adults to an anti-smoking communication. Respondents were asked to indicate how much they agreed or disagreed with the items (as the items were in the form of short statements) on a five point Likert-type scale $(1=$ Strongly Disagree to $5=$ Strongly Agree $)$. Example item: "I believe that if I don't smoke that often I am not under any risk"."
Even if I know something is bad for my health (e.g. smoking, sunbathing), if it gives me pleasure, it's worth it "Higher scores indicate a stronger adaptive coping response.

\section{Severity damage}

We used the Severity damage scale used by Rayner, Baxter and Ilicic (2015) to measure the damage perceived when a person looks at a graphic image related to smoking. Interviewees were asked to rate the level of Severity Damage perceived (using a 7-point semantic differential scale $1=$ low, $7=$ high) after viewing an image described on design and procedure section. The time between seeing the photos and answering the questions was no more than $10 \mathrm{~min}$.

\section{Attitude towards smoking behavior}

To measure the Attitude Towards Smoking behavior we used the same scale employed by Dickinson-Delaporte and Holmes (2011); the Attitude Towards Smoking test was designed to be used for researching both adolescent and adult populations when attempting to obtain attitudes towards smoking (DickinsonDelaporte \& Holmes, 2011; Shore et al., 2000). The attitude towards the behavior of smoking is the outcome variable in our study. Attitudes are usually investigated by threat study and include a variety of contexts (drug use, drunk driving, etc). A five-point Likert type scale consisted of 17 items from 'Strongly Disagree' to 'Strongly Agree': higher scores show a negative attitude towards smoking, while lower scores show a positive attitude towards smoking. Sample item: "I would be willing to form a close friendship with a smoker".

\section{Data analyses strategy}

The analysis of the data on our sample was mainly conducted with the models of structural equations. We completed the tests in AMOS 20.0 (Arbuckle \& Wothke, 1999), applying the maximumlikelihood method. Firstly, a confirmatory factor analysis (CFA) was used to test the model fit of the measurement model (Byrne, 2001), in order to produce a measurement model for the latent factors of Gravity Damage and Adaptive/Maladaptive Coping. In addition to the chi-square $(\chi 2)$ test, to verify the goodness of fit of our sample, we added other important indices: the comparative fit index (CFI), the Tucker- Lewis index (TLI), the Root Mean Square Error of Approximation (RMSEA), the (Non) Normed Fit Index (NNFI) of .95 indicates the model of interest improves the fit by $95 \%$ relative to the null model and the Standardized Root Mean Square Residual (SRMR) measure. The Akaike Information Criterion (AIC) and Bayesian Information Criterion (BIC) was also presented (lower values indicate better fit). Chi-square is sensitive to sample size and may therefore vary, Kline (2005) recommends analyzing the ratio chi-square/degrees of freedom (df), if $\chi^{2} / \mathrm{df}$ is greater than 3 it represents an inadequate fit. The indirect effect was tested using a bootstrap estimation approach on 2000 samples and a correct percentile method for $95 \%$ bias (Hayes \& Scharkow, 2013). We also tested the hypothesis of partial invariance with respect to the smoking/non-smoking variable with equality constraints between the groups.

Other well-known analytical tools, such as correlations, were also used, implemented by using SPSS 20.0. In order to optimize the sample size, missing values for the relevant items were estimated using the Expectation Maximization method. None of the items had more than $5 \%$ missing values, indicating that this option was appropriate for use (Tabachnick \& Fidell, 2007). 


\section{Ethical Statement}

All subjects gave their informed consent for inclusion before they participated in the study conducted in accordance with the Declaration of Helsinki. The study was conducted in accordance with the ethical standards established by the Italian National Psychological Association and approved by the IERB of the Department of Education Sciences on 29 July 2019.

\section{Results}

\section{Descriptive statistics of the scales, alpha and correlations}

Descriptive statistics of the scales (means and standard deviations), Cronbach's alphas and intercorrelations among the variables are reported in Table 1. The results confirm data reported in the literature, the correlation matrix showed that Smoking Attitude is significantly correlated with Adaptive/Maladaptive Coping $(r=.22, p>.01)$ and Severity Damage $(r=.29, p<.01)$. When a person develops a higher adaptive response, the more he will develop an attitude of rejection of smoking. Pearson correlation coefficients indicate a significant positive correlation between smoking attitudes and Trust of authority $(\mathrm{r}=.26, \mathrm{p}<.01)$ and a significant negative correlation with Freedom Resistance $(r=-.34$, $\mathrm{p}<.01$ ). Finally, Gravity Damage positively correlates with Individual Responsibility $(\mathrm{r}=.66, \mathrm{p}<.01)$.

\section{CFA confirmatory of the model's variables}

Confirmatory factor analyses of the variables were performed using robust maximum likelihood estimation to examine the fit of model. Two different models were tested and compared. The first model incorporated four factors considering all scales with a single factor structure. The results show a significant chi-square value $[\chi 2(10)=36.605, \mathrm{p}<.05]$ but the values of the other fit indices were: $\mathrm{NNFI}=.69 ; \mathrm{CFI}=.85 ; \mathrm{RMSEA}=.16$ wit $\mathrm{C} . \mathrm{I} .=.084-.101$; $\mathrm{SRMR}=.08$. Moreover, the AIC and BIC values were, 183.417 and 342.258 respectively. We thus tested a second model of CFA to check if a better fit was possible. The second CFA model included seven factors and considered Health Resistance not as a single measure but a factorial structure of second-order four factors. The results of this model provided a better fit: $\chi 2(15)=26.652, \mathrm{p}<.001$; $\mathrm{NNFI}=.91 ; \mathrm{CFI}=.98 ; \mathrm{RMSEA}=.08$ with $\mathrm{C} . \mathrm{I}=.047-.138$; $\mathrm{SRMR}=.04$, the AIC and BIC values were smaller, 65.652 and 144.548 respectively. This second model fitted the data significantly better than the first.

\section{Multiple mediation analysis}

Multiple mediation analysis was conducted using AMOS software. The effects of multiple mediator variables can be tested in two ways: individually and simultaneously. In our study, the choice was simultaneous testing, because the advantage is the ability to learn the effect of a mediator and the other mediator is independent of the mediators influence on each other, the strategy is try to evaluate the direct and indirect effects (Chen \& Hung, 2016). To test the model, Smoking Attitude was entered as the dependent variables, the four factors of Health Resistance (individual responsibility, skepticism, trust of authority and freedom/resistance) as independent variables; Adaptive/Maladaptive coping and Severity Damage were entered as mediators. Bias corrected (BC) confidence intervals were used with the bootstrapping (2000 samples) method in order to obtain more powerful confidence interval (CI-95\%) limits for indirect effects (Preacher \& Hayes, 2008).

\section{Direct effects}

The main results showed that there is a direct effect of all four factors of Health Resistance (HR) on smoking attitude, thus supporting hypothesis 1. (H1, HR_Skepticism, $\beta=-.26, p<.001$; HR_Freedom/Resistance, $\quad \beta=-.37, \quad \mathrm{p}<.001 ; \quad$ HR_Individual Responsability, $\beta=-.13, p<.05$; HR_Trust of Authority, $\beta=.34$, $\mathrm{p}<.001)$. In addition, the path from HR_Freedom/Resistance to Severity Damage is significant $(\beta=-.21, p<.05)$ as is the path from HR_Freedom/Resistance to Adaptive/Maladaptive coping ( $\beta=-.45$, $\mathrm{p}<.001)$ the path from HR_Trust of Authority to Adaptive/Maladaptive coping $(\beta=-.18, p<.05)$ and the path fromSeverity Damage to Smoking attitude $(\beta=-.13, p<.05)$. Health Resistance linked to the desire for freedom generally predicts the consumer's negative behavior towards smoking (Figure 2).

\section{Indirect effects}

With regard to hypothesis 2 , we initially assumed that the emotion of fear and the consequent impact on severity damage has a mediating effect (indirect effect) on the relationship between Health Resistance and Smoking Attitudes, this is confirmed by the relationship between Freedom/Resistance and Smoking Attitudes, it is mediated by the indirect effect of Severity Damage $(\mathrm{H} 2, \beta=.06$, $\mathrm{p}<.001 ; \mathrm{SE}=.03,95 \% \mathrm{CI}=.023, .305)$, while with regard to hypothesis 3 , it is only partially confirmed, coping responses have an indirect effect on the relationship between behaviors of freedom of Health Resistance and Attitude Towards Smoking [ $\left(\mathrm{H} 3_{\mathrm{a}}\right), \beta=.08$, $\mathrm{p}<.001 ; \mathrm{SE}=.03,95 \% \mathrm{CI}=.045, .267]$ and between the sense of trust in authorities and attitude towards smoking $\left[\left(\mathrm{H} 3_{\mathrm{a}}\right), \beta=.06, \mathrm{p}<.001\right.$;

Table 1. Descriptive statistics, Alpha and correlations of main variables $\mathrm{N}=260$ (HR: Health Resistance).

\begin{tabular}{|c|c|c|c|c|c|c|c|c|c|c|}
\hline & Mean & SD & $\alpha$ & 1 & 2 & 3 & 4 & 5 & 6 & 7 \\
\hline 1 HR_Skepticism & 2.73 & .74 & .69 & - & & & & & & \\
\hline 2.HR_Freedom/Resistance & 2.56 & .67 & .78 & $.55^{* *}$ & - & & & & & \\
\hline 3.HR_Individual responsibility & 3.59 & .53 & .80 & $.41^{* *}$ & $.34^{* *}$ & - & & & & \\
\hline 4.HR_Trust of authority & 3.49 & .71 & .84 & $.14^{*}$ & .10 & $.22 * *$ & - & & & \\
\hline 5.Total Health Resistance & 50.85 & 8.12 & .78 & $.80 * *$ & $.82^{* *}$ & $.65^{* *}$ & $.41^{* *}$ & - & & \\
\hline 6. Adaptive/Maladaptive coping & 32.57 & 2.97 & .79 & $-.41 * *$ & $-.47 * *$ & $-.15^{* *}$ & $-.22 * *$ & $-.50 * *$ & - & \\
\hline 7. Severity Damage & 5.83 & 1.41 & - & .04 & -.02 & $.66^{* *}$ & -.11 & -.05 & .05 & - \\
\hline 8. Smoking Attitude & 57.92 & 8.37 & .77 & -.04 & $-.34 * *$ & -.11 & $.26^{* *}$ & $-.16^{* *}$ & $.22^{* *}$ & $.29 * *$ \\
\hline
\end{tabular}


$\mathrm{SE}=.03,95 \% \mathrm{CI}=-.042, .070]$, in the first case it is the desire to justify the choice made that stimulates the adaptive response in the smoke comparisons, while in the second one is the trust in authorities to be mediated by an attitude of resistance towards smoking (Table 2).

\section{Multigroup analysis}

Multigroup structural equation modeling (SEM) was used for multivariable analysis; AMOS 25.0 uses a procedure known as full information maximum likelihood in the presence of missing data. Then models with and without constraining of paths across the groups were fitted. The path coefficients were compared between the groups for statistically significant differences. Fit statistics included chi-square, the comparative fit index (CFI) $(>0.90)$, the root mean squared error of approximation (RMSEA) $(<0.06)$, and chi-square to degrees of freedom ratio $(\mathrm{Hu})$. Unstandardized and standardized regression coefficients were reported. In our research, the two groups that were compared were smokers/non-smokers, in order to see the different impact between health resistance and attitudes to smoking compared to the severity perceived by the image and the consequent adaptive responses of coping. Hypothesis 4 is confirmed, there are important significant differences between the smokers and non-smokers group. First, HR _ Trust of Authority predicts a coping (adaptive/maladaptive) response for non-smokers $(\beta=-.29, p<.001)$ compared to smokers $(\beta=-.05, \mathrm{~ns})$. Smokers $(\beta=.11 ; p<.0 .5)$, compared to the perception of image severity, have a higher freedom resistance to smoking than non-smokers $(\beta=-.04$ ns). Furthermore, individual responsibility predicts the attitude of greater resistance to smoking in the non-smoker group $(\beta=.18, p$ $<.001)$ than the smoker group ( $\beta=-.07, n s)$. Exposure to severity of damage produces a significant effect only on non-smokers $(\beta=-.10$, $\mathrm{p}<.05)$ that was more sensitive than smokers to the images shown $(\beta=.09 ; \mathrm{ns})$ (Table 3).

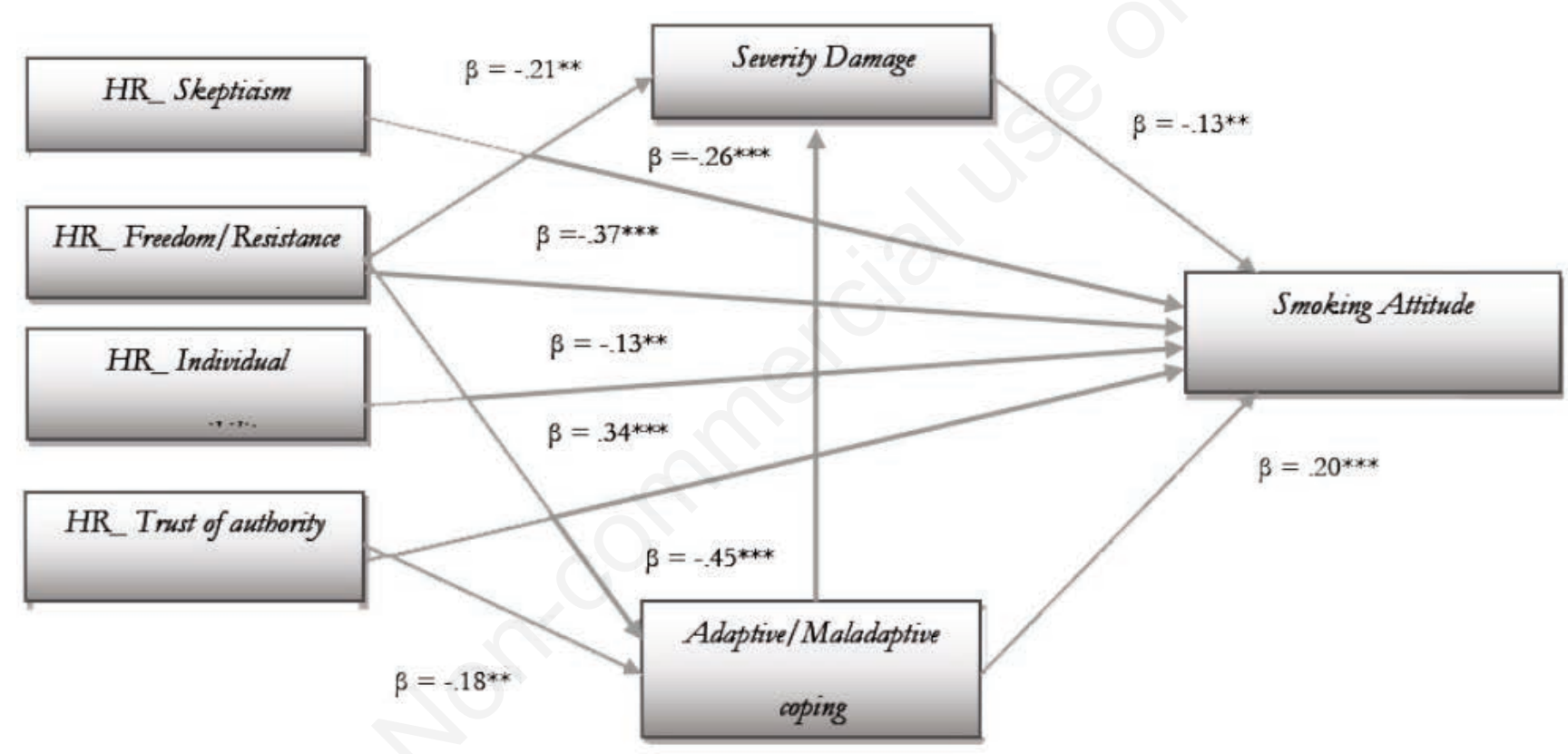

Figure 2. Path diagram of the variables inserted in the mediation model $\left({ }^{* *} \mathrm{p}<0.05,{ }^{* * *} \mathrm{p}<0.001\right)$.

Table 2. Standardized indirect effects from health resistance to smoking attitudes through severity damage and adaptive/maladaptive coping.

\begin{tabular}{|c|c|c|c|c|c|}
\hline Predictor & Mediator & Outcome & Estimate & SE & $\begin{array}{c}\text { BC } 95 \% \text { C } \\
\text { LL / UL }\end{array}$ \\
\hline HR_Skepticism & Severity Damage & Smoking Attitude & .02 & .02 & $.001 / .115$ \\
\hline HR_Freedom/Resistance & Severity Damage & Smoking Attitude & $.06^{*}$ & .03 & $.023 / .305$ \\
\hline HR_Individual responsibility & Severity Damage & Smoking Attitude & -.02 & .02 & $-.10 /-.026$ \\
\hline HR_ Trust of authority & Gravity Damage & Smoking Attitude & .01 & .02 & $-.033 / .004$ \\
\hline HR_Freedom/Resistance & Adaptive/Maladaptive coping & Smoking Attitude & $.08 *$ & .03 & $.045 / .267$ \\
\hline HR_ Trust of authority & Adaptive/Maladaptive coping & Smoking Attitude & $.06^{*}$ & .03 & $-.042 / .070$ \\
\hline Severity Damage & Adaptive/Maladaptive Coping & Smoking Attitude & $.08 *$ & .03 & $.089 / .350$ \\
\hline
\end{tabular}




\section{Discussion}

A large part of previous research identified that anti-smoking advertisement targeting adolescents (Pechmann \& Goldberg, 1998; Smith \& Stutts, 2006), neglecting the age range immediately after adolescence, which, instead, represents an important risk group; tobacco dependence almost always starts in childhood or adolescence (Farber et al., 2015; Buscemi et al., 2016); after adolescence because of the dependence that smoking creates, it becomes very complicated to stop smoking, thus, it seemed really interesting to observe the reactions of this specific group to antismoking advertisement. The findings of this study provide new evidence on many aspects of threat appeal campaigns. First of all, our results highlight the connection between coping response and smoking attitude: when people develop a higher adaptive response, they develop a form of denial against the smoking habit. In fact, protection motivation as intended by Ordered Protection Motivation Theory (Rogers, 1983) is the result of coping appraisal. This protection motivation triggers an individual's coping response; in this case, people develop a rejection behavior towards smoking. However, is protection motivation able to defend people from health resistance? Our results, highlighted above in the paragraph "direct effect" confirm that different forms of health resistance predict the attitude towards smoking as stated in our first hypothesis. In detail, all four factors of health resistance - intended as psychological reactance -, have a direct effect on the attitude towards smoking. This may confirm, as stated in the literature (Miller \& Quick, 2010), that graphic imagery on cigarette packages could generate Health Resistance; thus, triggering the consumer's negative behavior towards smoking (Platania et al., 2017). In addition, recent research applying the theory of psychological reactance regarding the use of tobacco has shown that the relief experienced from freedom threat became a predictor of tobacco use and also a moderator of perceived effectiveness of antismoking messages (Miller \& Quick, 2010). However, as suggested by Dickinson-Delaporte \& Holmes (2011), other variables may contribute to the resistance to the health message and continued smoking. We identified variables of "severity damage", perceived by observing graphic images, and "coping response" as contributing to the use of tobacco. The indirect effect of multiple mediation confirmed that the perception of damage caused by exposure to the images is able to mediate the relationship between the forms of health resistance elicited by the desire for freedom and attitude towards smoking. This means that, at first exposure to the graphic images triggers reactance, but, immediately after, when people were invited to evaluate the severity of damage, their reasoned appraisal mitigates/attenuates the impact on the attitude towards smoking. Hence, exposure to the images with a strong, high level of threat appeal induces the individual to reflect on his state of health attenuating the desire to smoke. We obtained the same results for coping response: in the consumer is activated significant responses related to the perception of danger, trust of authority, and freedom resistance which are moderated by coping response. Relevant insights are emphasized by Multigroup Analysis that compares the two groups offering us important indications about the effect exerted by health resistance on smokers and non-smokers. In brief, when people are induced to reason about smoke damage showing them threat appeal images, and evaluate their own coping strategy, their need to smoke is attenuated.

The comparison between smokers and non-smokers allowed us to better understand the role played by health resistance in the two groups, and the meaning that anti-smoking campaigns assume. These results suggest that the impact of graphic images on tobacco packaging may be undermined by individual reactions, especially reactance. As stated by LaVoie et al., with whom our results are in line, "the messages designed to deter smoking behaviors ignite freedom threat appraisal, which precedes reactance, and, in turn, elevates source domineeringness" (p. 343). Addressing these problems from a social marketing perspective provides a deeper insight into people's perceptions, opinions and views of the social issues under investigation (Griffin \& O'Cass, 2004). Our results provide a greater understanding of the impact that health promotion and social marketing campaigns play in tobacco use management. This also suggest us that many adjustments should be made to make threat appeal campaigns more efficacious considering that every year smoking leads millions of people to serious diseases or even death.

Table 3. Summary of path analysis between variables of our model between the smoker/non-smoker groups with equality constraints between the groups.

\begin{tabular}{|c|c|c|c|c|c|}
\hline \multirow[t]{2}{*}{ Paths of interest } & & \multicolumn{2}{|c|}{ Smokers } & \multicolumn{2}{|c|}{ No smokers } \\
\hline & & $\mathrm{B}(\mathrm{SE})$ & $p$ & $\mathrm{~B}(\mathrm{SE})$ & $p$ \\
\hline HR_Trust of authority & Adaptive/Maladaptive coping & -.05 & ns & -.29 & $<.001$ \\
\hline HR_Freedom/Resistance & Adaptive/Maladaptive coping & -.45 & $<.001$ & -.39 & $<.001$ \\
\hline HR_Freedom/Resistance & Severity Damage & .11 & $<.05$ & -.04 & ns \\
\hline Adaptive/Maladaptive coping & Severity Damage & .20 & $<.001$ & -.05 & ns \\
\hline Adaptive/Maladaptive coping & Smoking Attitude & .28 & $<.001$ & .24 & $<.001$ \\
\hline HR_Skepticism & Adaptive/Maladaptive coping & .12 & $<.05$ & .28 & $<.001$ \\
\hline HR_Freedom/Resistance & Smoking Attitude & -.32 & $<.001$ & -.01 & ns \\
\hline HR_Individual Responsibility & Smoking Attitude & -.07 & $\mathrm{~ns}$ & .18 & $<.001$ \\
\hline HR_Trust of Authority & Smoking Attitude & .19 & $<.001$ & .52 & $<.001$ \\
\hline Severity Damage & Smoking Attitude & .09 & ns & -.10 & $<.05$ \\
\hline \multicolumn{6}{|l|}{ Models } \\
\hline $\mathrm{M}_{1}$ & $\chi^{2}(10)=23.319, p<.001 ; \mathrm{CFI}=.97 ; \mathrm{RMSEA}=.071$ & & & & \\
\hline $\mathrm{M}_{2}$ & $\chi^{2}(12)=29.523, p<.001 ;$ CFI $=.97 ;$ RMSEA $=.064$ & & & & \\
\hline$\Delta \chi^{2} \mathrm{M}_{2}-\mathrm{M}^{1}$ & $\Delta \chi^{2}(2)=6.204 ; p<.05$ & & & & \\
\hline
\end{tabular}


The present study contributes to a body of knowledge in the threat appeal and smoking literature. Nevertheless, a number of methodological limitations should be noted. It is important to enlighten that our results are based on cross-sectional data and therefore it is not possible to draw conclusions about temporality or causation. This study reports on a group of young adults who are no longer adolescents but may not have reached the maturity of adulthood (Arnett, 2007) making them a sample that has characteristics of both younger and older adults. Not only, our sample was composed only by university students, so, generalizability is still restricted. However, we found no studies examining the difference between young adults attending university and not. A future study comparing these populations should be useful to better understand how status may influence attitudes toward threat appeal campaign. Another limit of this study was minimal consideration of how common mental health conditions like stress, anxiety and depression relate to cigarette smoking, further investigations should include them to better understand the vastness of the phenomenon. The role of coping response should be studied further; it could be interesting to understand if personality traits influence health resistance and the relation with smoking attitude. Considering the role that health resistance plays in antismoking campaigns it would be interesting to understand how to stem individual reactance and make threat appeal more convincing and persuasive.

\section{Conclusions}

These multigroup analyses emphasize, in general, how there is a greater form of resistance by smokers compared to non-smokers, highlighting how health resistance plays an important role in weakening the effect of fears-based campaigns, which reduces the effect of the graphic image. Our research has found that trust of authority predicts a coping response only in non-smokers while smokers remain indifferent; smokers placed in front of severity damage image develop greater resistance because they feel threatened in their freedom to choose what to do with their life (Platania et al. 2017b). Non-smokers do not develop any health resistance remaining affected by the message contained in the images. Moreover, individual responsibility induces a greater resistance to smoking only in the non-smokers group, and severity damage makes only the non-smokers group more sensitive. Overall, "Experiencing reactance toward a message and, therefore, perceiving the source as more domineering, could potentially create more negative attitudes toward the message or the source. Negative attitudes toward the source may reduce behavioral intentions, an operationalization of persuasiveness, of graphic image warning labels as an antitobacco strategy" (LaVoie et al., 428). Using graphic warning images on tobacco packaging should be carefully considered before its implementation. Considering the studies cited above, the effectiveness of fear appeals on the social markets should be further studied to really understand the weight of reactance in anti-smoking campaigns.

\section{References}

Arbuckle, J.L., \& Wothke, W. (1999). AMOS 4.0 User's Guide. Chicago, IL: Smallwaters Corp.

Arnett, J.J. (2007). Emerging adulthood: What is it, and what is it good for? Childhood Development Perspectives, 1, 68-73.
Beaudoin, C.E. (2002). Exploring antismoking ads: Appeals, themes, and consequences. Journal of Health Communication, 7(2), 123-137.

Buscemi A., Rapisarda A., Platania, S., Maida F., Brancat D., Petralia M.C., Di Nuovo S., Giustiniani S., Caldarella L., Blandino M.G., Grillo G., Barbagallo G., Coco O., Perciavalle Va., Perciavalle V., Armenia G., \& Coco M. (2016). The Woman In Pregnancy: Body Care By Knowing Of Alternative Medicine. In Acta Medica Mediterranea, 32(4), 953-958.

Byrne, B.M. (2001). Structural equation modeling with AMOS: Basic concepts, applications, and programming. Mahwah, NJ: Lawrence Erlbaum.

Chen, L.J., \& Hung, H.C. (2016). The indirect effect in multiple mediators model by structural equation modeling. European Journal of Business, Economics and Accountancy, 4(3), 36-43.

Crossley, M.L. (2002). Resistance to health promotion: A preliminary comparative investigation of British and Australian students. Health Education, 102, 289-299.

Dickinson-Delaporte, S.J., \& Holmes, M. D. (2011). Threat appeal communications: The interplay between health resistance and cognitive appraisal processes. Journal of Marketing Communications, 17(2), 107-125.

Erceg-Hurn DM, Steed LG. (2011). Does exposure to cigarette health warnings elicit psychological reactance in smokers? Journal of Applied Social Psychology; 41, 219-237.

Farber, H.J., Groner, J., Walley, S., \& Nelson, K. (2015). Protecting children from tobacco, nicotine, and tobacco smoke. Pediatrics, 136,1439-1467.

Germain, D., Wakefield, M.A., \& Durkin, S.J. (2010). Adolescents' perceptions of cigarette brand image: does plain packaging make a difference?. Journal of Adolescent health, 46(4), 385392.

Guttman, N., \& Ressler, W.H. (2001). On being responsible: Ethical issues in appeals to personal responsibility in health campaigns. Journal of Health Communication, 6(2), 117-136.

Hammond, D., Fong, G.T., Borland, R., Cummings, K.M., McNeill, A., \& Driezen, P. (2007). Text and graphic warnings on cigarette packages: findings from the international tobacco control four country study. American journal of preventive medicine, 32(3), 202-209.

Hammond, D., McDonald, P. W., Fong, G.T., Brown, K.S., \& Cameron, R. (2004). The impact of cigarette warning labels and smoke-free bylaws on smoking cessation. Canadian Journal of Public Health, 95(3), 201-204.

Hayes, A. F., \& Scharkow, M. (2013). The relative trustworthiness of inferential tests of the indirect effect in statistical mediation analysis. Psychological Science, 24, 1918-1927.

Hu, L.T, \& Bentler, P.M. (1999). Cutoff criteria for fit indexes in covariance structure analysis: Conventional criteria versus new alternatives. Structural Equation Modeling: A Multidisciplinary Journal, 6(1), 1-55.

Griffin, D., \& O'Cass, A. (2004). Social marketing: Who really gets the message? Journal of Nonprofit \& Public Sector Marketing, 12(2), 129-147.

Kang, J., \& Lin, C.A. (2015). Effects of message framing and visual-fear appeals on smoker responses to antismoking ads. Journal of Health Communication, 20, 647-655.

Kline, R.B. (2005). Principle and practice of structural equation modeling. New York, NY: Guilford Press.

LaVoie, N.R., Quick, B.L., Riles, J.M., \& Lambert, N.J. (2017). Are graphic cigarette warning labels an effective message strategy? A test of psychological reactance theory and source appraisal. Communication Research, 44, 416-436. 
Manyiwa, S., \& Brennan, R. (2012). Fear appeals in anti-smoking advertising: How important is self-efficacy? Journal of Marketing Management, 28(11-12), 1419-1437.

McCrae, R.R. (1984). Situational determinants of coping responses: Loss, threat, and challenge. Journal of Personality and Social Psychology, 46, 919-928.

Miller, C.H., \& Quick, B.L. (2010). Sensation seeking and psychological reactance as health risk predictors for an emerging adult population. Health Communication, 25, 266275.

Ministry of Health. (2018). La nostra salute [Ministry of health, our health] Retrieved from http://www.salute.gov.it/ portale/salute/p1_5.jsp?id=53\&area=Vivi_sano

Ministry of Health. (2017). Prevenzione e controllo del tabagismo: Rapporto anno 2017 [Ministry of health, prevention and control of smoking: report 2017]. Retrieved from http://www.salute.gov.it/portale/temi/p2_6.jsp?lingua=italiano\& id $=467 \&$ area $=$ stiliVita\&menu $=$ fumo

Moodie, C., \& Ford, A. (2011). Young adult smokers' perceptions of cigarette pack innovation, pack colour and plain packaging. Australasian Marketing Journal (AMJ), 19(3), 174180.

O’Hegarty, M., Pederson, L.L., Nelson, D.E., Mowery, P., Gable, J.M., \& Wortley, P. (2006). Reactions of young adult smokers to warning labels on cigarette packages. American journal of preventive medicine, 30(6), 467-473.

Pacifici, R. (2017). Rapporto nazionale sul fumo, Roma. Retrieved from fumo/index.php?lang $=1 \&$ id $=371 \&$ tipo $=4$

Paek, H.J., Kim, S., Hove, T., \& Huh, J.Y. (2014). Reduced harm or another gateway to smoking? Source, message, and information characteristics of e-cigarette videos on youtube. Journal of Health Communication, 19, 545-560.

Pechmann, C. \& Goldberg, M. (1998) Evaluation of Ad Strategies for Preventing Youth Tobacco Use. Berkeley, CA: California Tobacco-Related Disease Research Program.

Perloff, P. (2003). The dynamics of persuasion: Communication and attitudes in the 21th century. Mahwah, NJ: Lawrence Erlbaum Associates.

Peters, E., Romer, D., Slovic, P., Jamieson, K. H., Wharfield, L., Mertz, C.K., \& Carpenter, S.M. (2007). The impact and acceptability of Canadian-style cigarette warning labels among US smokers and nonsmokers. Nicotine \& Tobacco Research, 9(4), 473-481.
Platania S., Gruttadauria, S., Citelli, G., Giambrone L., Di Nuovo, S. (2017) Associations of Thalassemia Major and satisfaction with quality of life: The mediating effect of social support, In Health Psychology Open, July-December 2017: 1-9. DOI: $10.1177 / 2055102917742054$.

Platania S., Morando M., Santisi G., (2017). The Phenomenon Of Brand Hate: Analysis Of Predictors And Outcomes, In Quality Access to Success 18(S2), pp.342-347. ISSN 1582-2559.

Preacher, K.J., \& Hayes, A.F. (2008). Asymptotic and resampling strategies for assessing and comparing indirect effects in multiple mediator models. Behavior Research Methods, 40, 879-891.

Rayner, E., Baxter, S. M., \& Ilicic, J. (2015). Smoker's recall of fear appeal imagery: Examining the effect of fear intensity and fear type. Australasian Marketing Journal (AMJ), 23(1), 61-66.

Rippetoe, P.A., \& Rogers, R.W. (1987). Effects of components of protection-motivation theory on adaptive and maladaptive coping with a health threat. Journal of Personality and Social Psychology, 52, 596-604.

Rogers, R.W. (1983). Cognitive and physiological processes in fear appeals and attitude change: A revised theory of protection motivation. In J. Capioppo \& R. Petty (Eds.), Social psychology (pp. 153-176). New York, NY: Guilford Press.

Schoenbachler, D.D., \& Whittler, T.E. (1996). Adolescent processing of social and physical threat communications. Journal of Advertising, 25(4), 37-54.

Shore, T.H., Tashchian, A., \& Adams, J.S. (2000). Development and validation of a scale measuring attitudes toward smoking. The Journal of Social Psychology, 140, 615-623.

Smith, K.H., \& Stutts, M.A. (2006). The Influence of Individual Factors on the Effectiveness of Message Content in Antismoking Advertisements Aimed at Adolescents. Journal of Consumer Affairs, 40, 261-293.

Tabachnick, B.G., \& Fidell, L.S. (2007). Using multivariate statistics. Boston, MA: Allyn \& Bacon.

Tanner, J.F., Hunt, J.B., \& Eppright, D.R. (1991). The protection motivation model: A normative model of fear appeals. Journal of Marketing, 55(3), 36-45.

World Health Organization. (2017). WHO report on the global tobacco epidemic, 2017: enforcing bans on tobacco advertising, promotion and sponsorship. Geneva: WHO

World Health Organization. (2013). The World Health Report 2013. World Health Organization. 